\title{
Radiation resistance of high frequency ultrasonic devices for distance measurement in the RHF
}

\author{
Meriem Chrifi Alaoui, Emmanuel Le Clézio, Member IEEE, \\ Gilles Despaux, Member IEEE \\ University of Montpellier, CNRS, IES UMR 5214, CC 05 003, \\ 860 Rue de Saint Priest, F-34000 Montpellier \\ Email: emmanuel.le-clezio@umontpellier.fr
}

\author{
Yoann Calzavara \\ Institute Laue Langevin - ILL \\ 71 Avenue des Martyrs, \\ F-38000 Grenoble \\ Email: calzavara@ill.fr
}

\begin{abstract}
The fuel element plates of research reactors are subjected to swelling phenomena. These structure modifications impact an initial inter-plate distance of $1.8 \mathrm{~mm}$. An ultrasonic device has been developed to investigate this parameter. With a $1 \mathrm{~mm}$ thickness, it relies on two transducers linked to an electronic system. The feasibility of the distance measurement has been proved in a previous study and the irradiation impact on the transducer components is here studied. To do so, a radiation resistance experiment was realized in the Arc-Nucleart Institute of Grenoble. It allowed the study of the influence of radiations on the device active and passive components' characteristics.
\end{abstract}

\section{INTRODUCTION}

In a conversion program aiming to the introduction of Low Enriched Uranium in research reactors, investigations are conducted to identify convenient fuel types. Integrated in this program, the Institute Laue Langevin (ILL) studies the conversion of the High Flux Reactor (RHF) of Grenoble. Its fuel element is made of plates separated by a distance of $1.8 \mathrm{~mm}$. During the reactor life cycle, irradiations induce swelling impacting this so-called channel-gap.

To monitor its variations, a non-destructive ultrasonic device was developed to be inserted between two plates. It includes two manufactured high frequency transducers, inserted in a $1 \mathrm{~mm}$ blade and related to electronic instruments. The distance measurement feasibility being proved during a RHF experiment [1], the irradiation impact on the transducer components is here studied.

In this view, tests were performed on 10 transducers with central frequencies ranging from $38 \mathrm{MHz}$ to $160 \mathrm{MHz}$. The device components were irradiated during 4 months in the ArcNucleart Institute of Grenoble [2] and the resulting irradiation corresponded to $3500 \mathrm{kGy}$.

The first section of this paper presents the distance measurement configuration and the proposed ultrasonic device. To analyze the irradiation impact, the second section displays the irradiator and the experimental set-up developed to monitor transducer responses. Results are presented in the last section.

\section{ULTRASONIC DEVICE CONCEPTION}

\section{A. Experimental constraints}

As presented in [1], performing distance measurement inside a RHF is quite complicated. First, the fuel element is placed 5 meters below the surface of a water pool. Then, the reactor is made of curved plates with a $1.8 \mathrm{~mm}$ interplate distance. Finally, the measurements take place in a radiative environment. To integrate these constraints, a device was proposed with a thickness limited to $1 \mathrm{~mm}$.

\section{B. Distance measurement principle}

The ultrasonic device structure is presented on figure 1 where the inter-plate distance $d$ depends on the distance $h$

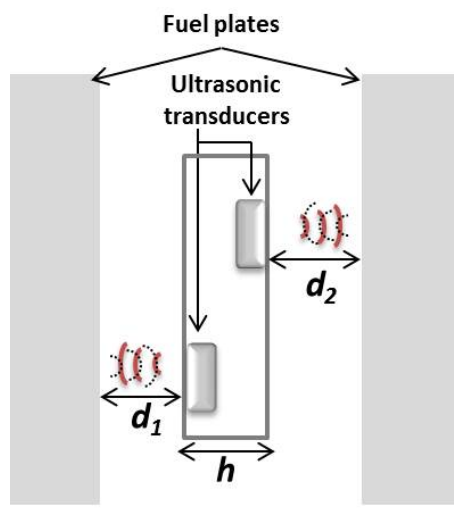

Fig. 1: Inter-plate distance measurement principle.

between the two transducers and distances $d_{1}$ and $d_{2}$ measured through the estimation of the time of flight [3] of ultrasonic waves propagating in the coupling medium $t_{1}$ and $t_{2}$ :

$$
d=h+V *\left(t_{1}+t_{2}\right) / 2
$$

where $V$ is the sound velocity in water. The feasibility of distance measurement has been proved in a previous study [1] and the irradiation impact on the transducer components is now studied.

\section{IRRADIATION EXPERIMENT}

\section{A. Experimental constraints}

10 transducers and several passive components were manufactured. To allow the identification of potentially structural effects, they were distributed in a broad frequency range corresponding to $[38-160] \mathrm{MHz}$. They were submitted to irradiation at the Arc-Nucleart Institute of Grenoble [2]. To 
estimate the utrasonic system evolution in a more than 10 hour RHF control, where the device is submitted to a flow of $300 \mathrm{kGy} / \mathrm{h}$, an irradiation was then performed up to a total of $3500 \mathrm{kGy}$. Two transducers were not stressed to observe environmental impact.

\section{B. Arc-Nucleart Irradiator}

The Arc-Nucleart installation includes a water pool and a concrete irradiation cell as presented in figure 2 . The gamma sources are of Cobalt ${ }^{60} \mathrm{Co}$. The transducer elements were installed in the irradiation cell while the sources were in the pool. The irradiator rate ranges from $10 \mathrm{~Gy} / \mathrm{h}$ to $2 \mathrm{kGy} / \mathrm{h}$.

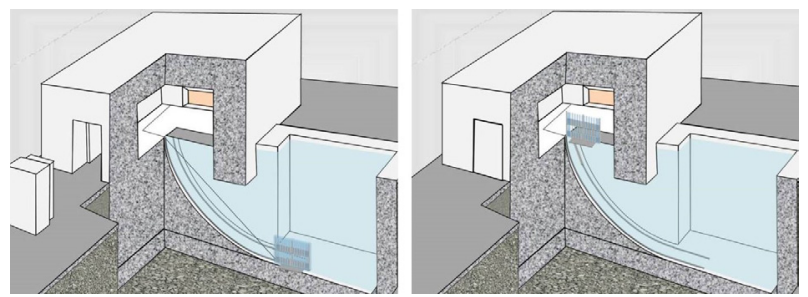

Fig. 2: Nuclear irradiator installation scheme.

For the experiment, a $1.4 \mathrm{kGy} / \mathrm{h}$ flow was applied yielding a more than 3 month long experiment. A specific set-up was then realized to allow a continuous monitoring.

\section{Experimental set-up}

The irradiated devices and passive components positioned in the irradiation cell are presented in figure 3. Communication

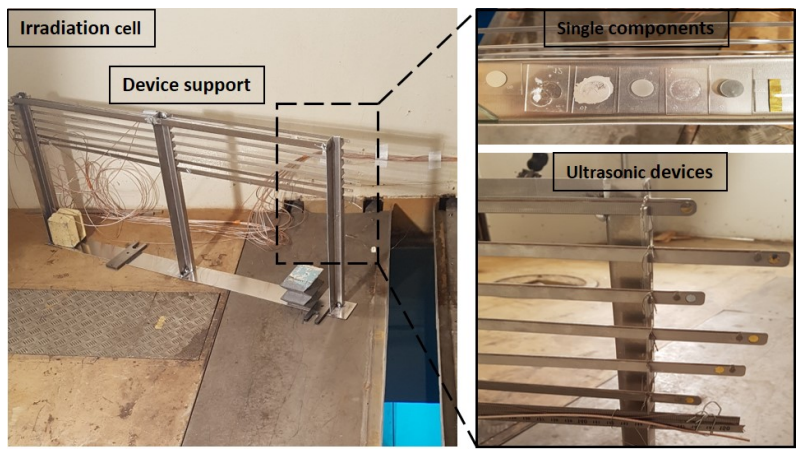

Fig. 3: Elements in the irradiation cell.

paths allow passage of cables linking the transducers to an electronic set-up including:

- A E8356A Agilent network analyzer for fast scanning, wide dynamic range and flexible connectivity traces.

- Acquisition cards inserted in a PXIe-1062 chassis:

- RF multiplexer switch module PXIe-2747 card, with dual 8 inputs and 2 outputs.

- PXIe-8135 controller as the interface between electronic components and the acquisition software.

\section{Data acquisition and processing}

For each transducer, a spectrum acquisition is realized every 6 minutes. To monitor acoustic echoes, an Inverse Fourier Transform and a digital bandpass filtering are applied. Then, a specific echo is extracted and its parameters allow the study of the transducer's behavior during the experiment. To analyze device's behavior, investigated echo parameters are: central frequency, bandwidth and amplitude.

\section{RESUlTS AND DISCUSSION}

\section{A. Distance measurement parameters' analyzes}

Two transducers' responses are here discussed. They correspond to a $113 \mathrm{MHz}$ reference transducer placed outside the irradiation cell (a) and a $87 \mathrm{MHz}$ irradiated transducer (b). The bandwidth spectrum of the reference transducer measured in the laboratory for 3 days and that obtained outside the irradiation cell are presented in figure 4(a) and (b) respectively. Those of the irradiated transducer are figure 5(a) and (b). These spectra reveal very few variation during irradiation

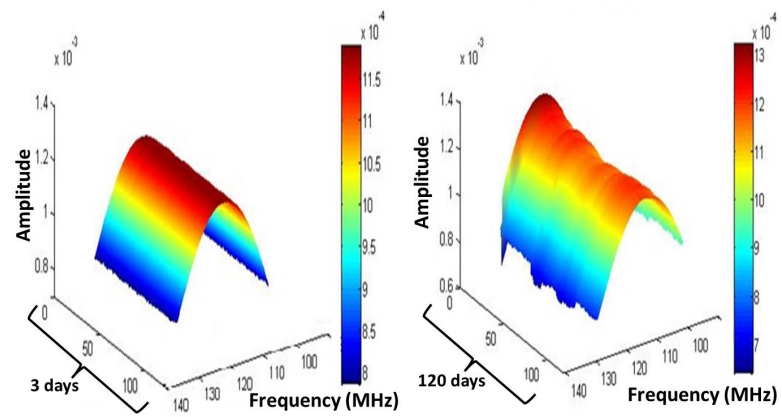

Fig. 4: Bandwidth spectra of the reference transducer (a) in the laboratory (b) outside the irradiation cell.
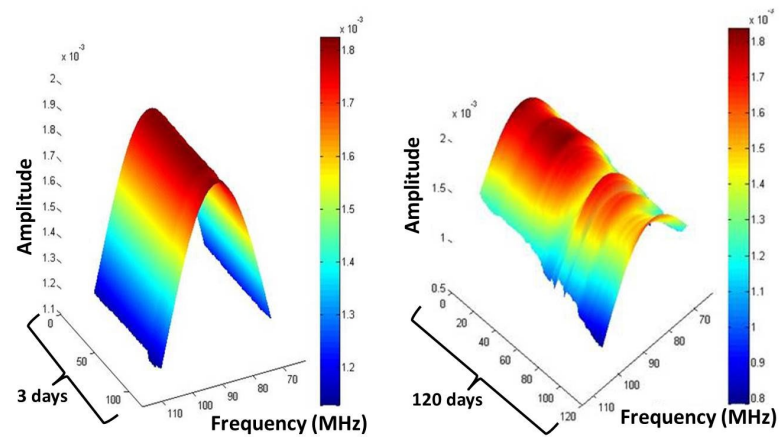

Fig. 5: Bandwidth spectra of the irradiated transducer (a) in the laboratory (b) inside the irradiation cell.

and a very good stability of the transducer characteristics can be stated. Indeed, the frequency, amplitude and bandwidth evolution of the reference transducer are presented in figure 6(a) and (b) and compared to that of the irradiated transducer in figure 7(a) and (b). For the reference transducer, the maximum frequency, amplitude and bandwidth variations are 

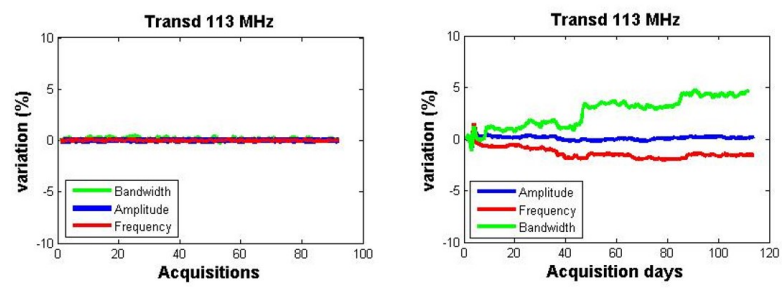

Fig. 6: Reference transducer spectra parameters' variation (a) at the laboratory (b) outside the irradiation cell.
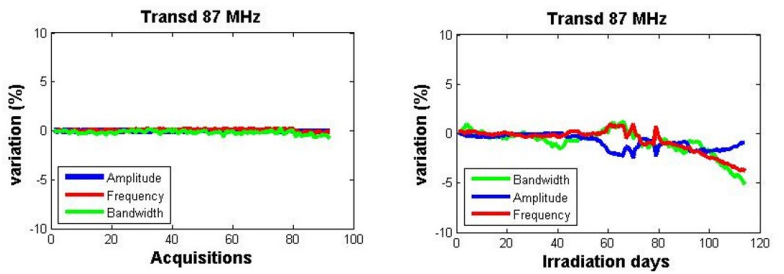

Fig. 7: Irradiated transducer spectra parameters' variation (a) at the laboratory (b) inside the irradiation cell.

of $2 \%, 1 \%$ and $4.8 \%$ respectively. For the irradiated transducer, they are equal to $4 \%, 2.4 \%$ and $5.1 \%$. These results clearly indicate a global stability of the transduction characteristics. In agreement with the previous results, the variations of the other transducers' parameters are presented in Table I with

\begin{tabular}{|c|c|c|c|}
\hline Element & $\begin{array}{c}\text { Frequency } \\
\text { variation }\end{array}$ & $\begin{array}{c}\text { Amplitude } \\
\text { variation }\end{array}$ & $\begin{array}{c}\text { Bandwidth } \\
\text { variation }\end{array}$ \\
\hline Transducer $38 \mathrm{MHz}$ & $8.0 \%$ & $5.0 \%$ & $4.7 \%$ \\
\hline Transducer $72 \mathrm{MHz}$ & $0.5 \%$ & $1.5 \%$ & $2.9 \%$ \\
\hline Transducer $78 \mathrm{MHz}$ & $1.5 \%$ & $3.2 \%$ & $1.3 \%$ \\
\hline Transducer $87 \mathrm{MHz}$ & $4.0 \%$ & $2.4 \%$ & $5.1 \%$ \\
\hline Transducer $97 \mathrm{MHz}$ & $8.0 \%$ & $3.4 \%$ & $6.0 \%$ \\
\hline Transducer $103 \mathrm{MHz}$ & $1.0 \%$ & $1.0 \%$ & $2.7 \%$ \\
\hline Transducer $116 \mathrm{MHz}$ & $3.0 \%$ & $4.5 \%$ & $3.0 \%$ \\
\hline Transducer $162 \mathrm{MHz}$ & $2.0 \%$ & $1.5 \%$ & $3.0 \%$ \\
\hline
\end{tabular}

TABLE I: Transducers parameters' maximum variations.

maximum variations of: $8 \%$ for frequency, $5 \%$ for amplitude and $6.0 \%$ for bandwidth.

\section{B. Passive elements}

1) Form and adhesion parameters: 4 elements were manufactured: adhesive, backing and conducting materials deposited on silica supports with a superposed silica, and a conducting material deposited without the second silica layer. Their comparison before and after irradiation is performed thanks to a TePla ultrasonic microscope [4] including a $200 \mathrm{MHz}$ transducer. Initial and after irradiation images are presented in figure 8 first and second lines respectively. They show that, for the $2^{\text {nd }}$ and $3^{\text {rd }}$ elements, disbonding phenomena appear on the contour area of material. The $4^{\text {th }}$ element presents a color modification and an ultrasonic signal attenuation indicating a potential increase in the material porosity. This point will be further studied in future works.

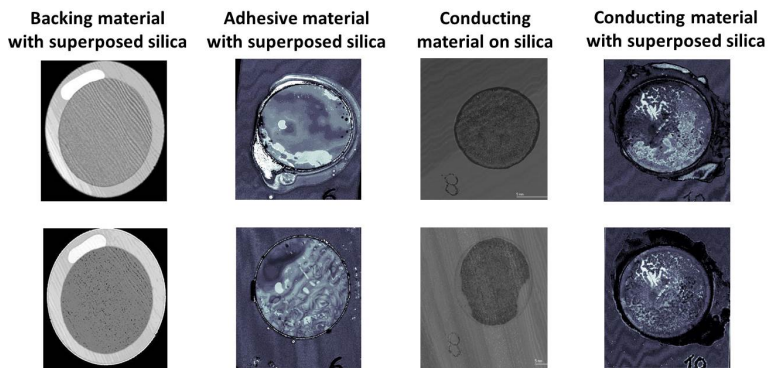

Fig. 8: Passive elements microscopic images.

2) Mechanical properties: Acoustic signatures [5] were realized on the 2 silica elements. Rayleigh velocity and Young modulus estimations are presented in table II, indicating a

\begin{tabular}{|c|c|c|c|}
\hline Element & $\begin{array}{c}\text { Pre-irradiation } \\
\text { properties }\end{array}$ & $\begin{array}{c}\text { Post-irradiation } \\
\text { properties }\end{array}$ & $\begin{array}{c}\text { Percentage } \\
\text { variation }\end{array}$ \\
\hline Silica type 1 & $\mathrm{V}_{R}=3395 \mathrm{~m} / \mathrm{s}$ & $\mathrm{V}_{R}=3338 \mathrm{~m} / \mathrm{s}$ & $1 \%$ \\
& $\mathrm{E}=71.86 \mathrm{GPa}$ & $\mathrm{E}=71.13 \mathrm{GPa}$ & \\
\hline Silica type 2 & $\mathrm{V}_{R}=3110 \mathrm{~m} / \mathrm{s}$ & $\mathrm{V}_{R}=3108 \mathrm{~m} / \mathrm{s}$ & $0.1 \%$ \\
& $\mathrm{E}=62.38 \mathrm{GPa}$ & $\mathrm{E}=62.30 \mathrm{GPa}$ & \\
\hline
\end{tabular}

TABLE II: Measured mechanical properties of the Silica elements.

negligible maximum variation of $1 \%$ after irradiation.

\section{CONCLUSION}

An irradiation experiment was realized on 10 ultrasonic transducers and passive components. A real-time monitoring system was developed to observe their responses to a 3500 kGy dose. Transducers' frequency, amplitude and bandwidth showed good stability along irradiation. For passive elements, forms and mechanical properties were compared before and after irradiation through acoustic microscopy and revealed high stability. These results clearly indicate that these device components can then be included in systems allowing more than 10 hours of continuous control of RHF fuel elements.

\section{ACKNOWLEDGMENT}

The authors would like to thank Y. Launay and O. Guillemard for their contributions to supports and devices manufacturing. Acknowledgments are also dedicated to L. Cortella and Arc-Nucleart members for their great help.

\section{REFERENCES}

[1] G. Zaz, E. Le Clézio, A. Dekious, M. Chrifi Alaoui, Y. Calzavara and G. Despaux. In-situ high-resolution measurement of RHF nuclear fuel plates' spacing. IEEE Transactions on Nuclear Science, 65, 2018.

[2] www.arc-nucleart.fr.

[3] D. Marioli, E. Sardini, and A. Taroni. Ultrasonic Distance measurement for Linear and Angular Position Control. IEEE Transactions on Instrumentation and measurement, 37, 1988.

[4] www.pva-analyticalsystems.com.

[5] M. Marchetti, D. Laux, L. Fongaro, T. Wiss, P. Van Uffelen, et al.. Physical and mechanical characterization of irradiated uranium dioxide with a broad burnup range and different dopants using acoustic microscopy Journal of Nuclear Materials, 494, pp.322 - 329, 2017. 